\title{
INFANTS AND CHILDREN IN THE ADULT WORLD OF AUTOMOBILE SAFETY DESIGN: PEDIATRIC AND ANATOMICAL CONSIDERATIONS FOR DESIGN OF CHILD RESTRAINTS*†
}

\author{
A. R. BURDI and D. F. HUELKE \\ Department of Anatomy, The University of Michigan Medical School, Ann Arbor, Mich. 48104, \\ U.S.A. \\ and \\ R. G. SNYDER \\ Biosciences Section and Department of Anthropology, The Highway Safety Research Institute, \\ The University of Michigan, Ann Arbor, Mich. 48108, U.S.A. \\ and \\ G. H. LOWREY \\ Department of Pediatrics, The University of Michigan Medical School, Ann Arbor, Mich. 48104, \\ U.S.A.

\begin{abstract}
The infant and child differ structurally from the adult in a number of ways which are critical to the design for protection against impact forces and for adequate occupant restraint systems. The purpose of this paper is to bring together a profile of the anatomy, anthropometry, growth, and development of the infant and child. Age differences related to the proper design of child restraint systems are emphasized. Problems discussed include child-adult structural differences, center of gravity of the body, the head mass in relation to the neck and general body proportions, positions of key organs, and biomechanical properties of tissues.
\end{abstract}

\section{INTRODUCTION}

NEARLY half of the 113,563 accidental deaths that occurred in the United States during 1967 were a consequence of motor vehicle injuries (National Safety Council, 1968). Of these 53,041 motor vehicle deaths, approximately 42,941 were automobile occupants. Children under $14 \mathrm{yr}$ of age accounted for 6 per cent of these deaths, with 2-3 per cent of the occupant deaths being infants and children under $5 \mathrm{yr}$ of age. In actual numbers there were 2700 deaths in the under 14 age group. In addition, of the 80,000 motor vehicle injuries in the under $5 \mathrm{yr}$ age, the majority ( 69 per cent) were in-car occupants. Of the 190,000 children between 5 and $14 \mathrm{yr}$ of age who were injured in all motor vehicle collisions, 56 per cent were occupants of automobiles.
Solutions to this problem will necessarily require the application of unique packaging and restraint concepts based on the particular body dimensions and organ relationships of the individuals in this young age range. A child's body dimensions, proportions, and biomechanical properties are so markedly different from that of an adult that a child cannot, for design purposes, be considered simply as a scaled-down adult.

Since there appears to be a lack of a single compilation of data concerning child design considerations, the purpose of this paper is to bring together a profile of the anatomy, anthropometry, growth and development of infants (birth to $1 \mathrm{yr}$ ) and children. This information is needed to provide a clearer and more valid basis for engineering design and

*Received 15 January 1969.

†Presented at the ASME Third Biomechanical and Human Factors Division Conference at the University of Michigan, Ann Arbor, June 12-13, 1969. 
packaging for occupant collision protection in the automotive environment, and will emphasize that infants and children are not miniature adults.

\section{GROWTH OF THE INFANT BODY AS A WHOLE}

Growth and development of the human body occurs continuously from birth through senescence (old age). Such development is sporadic and non-uniform; yet it does not occur haphazardly. For the most part incremental growth of any dimension or part of the body occurs according to predictable trends. Most body dimensions follow trends which involve rapid growth separated by a period of relatively slower or uniform growth. There are notable differences in the timing of these incremental growth spurts, for most tissues and organs of the body collectively reflect the general body growth. As an example, the brain grows rapidly during the period before birth and then slows considerably during the pre-school years. At birth the brain is typically 25 per cent of its adult size, although the body weight of the newborn is only about 5 per cent of adult weight (Stuart and Stevenson, 1950). Importantly, about half of the postnatal growth of the brain volume occurs during the first year of life, and attains about 75 per cent of its adult size by the end of the second year. By contrast, genital organs develop very slowly during this period of relatively high brain growth but, instead, reach their adult size during the second decade of life.

Subcutaneous tissue, or body fat, is a body component infrequently considered as a factor in the proper design of protective devices for the infant body. This tissue tends to increase rapidly in thickness during the first 9 months following birth, while growth of the body as a whole is much slower. After this period of high incremental change there is a period of less rapid growth, so that by $5 \mathrm{yr}$ of age the thickness of the subcutaneous layer is about half the thickness of the nine month old infant.
Loading of the body by strap-type restraints must occur in areas where the body is strongest, i.e., on solid skeletal elements. The fatty subcutaneous tissue often produces bulges or 'rolls' of flesh in the areas of placement of such restraint straps. Thus, proper positioning of restraint straps on the chubby $1-3$ yr old is difficult to maintain because of the abundance of this fatty tissue.

Changes in body weight similarly follow characteristic age group trends (Krogman, 1960; Krogman and Johnston, 1965; Martin and Thieme, 1954; and Meredith, 1963). From the 10th day after birth, when the postbirth weight loss is regained, there is a steady increase in weight so that during the first 3 months an average baby gains about $2 \mathrm{lb}$ per month, or nearly $1 \mathrm{oz}$ per day (Krogman, 1941). At 5 months the birth weight has doubled. Beginning at 6 months, there is only a 1-lb increment per month in weight so that the birth weight is tripled at the end of the 1 st yr and quadrupled at the end of the second. From this time on, the rate of increase in body weight gradually decreases during the 2 nd yr according to a factor of $\frac{1}{2} \mathrm{lb}$ per month (Krogman and Johnston, 1965). After the 2nd yr, gain in weight may become irregular and less predictable on a monthly basis. As a general pattern, after the 2nd yr and until the 9th yr there is a $5 \mathrm{lb}$ annual increment. Thus, at 5 yr the body weight is six times the birth weight and at $10 \mathrm{yr}$ of age the weight of the body is ten times the birth weight (Krogman, 1960).

Changes in body height and body proportions also have specific age trends (Figs. 1-3). The newborn child is approximately $20 \mathrm{in}$. in total body length. During the 1 st yr this height is increased by approximately $10 \mathrm{in}$. Until about the seventh year, total body length increases by about $3 \mathrm{in} / \mathrm{yr}$. After the 7 th yr, increases of $2 \mathrm{in} / \mathrm{yr}$ are typical until the pubertal spurt. In general, total body length should be doubled by the 4th yr and tripled by the 13th yr. The height of an adult is about twice the height of a $2 \mathrm{yr}$ old child. From 2 to 


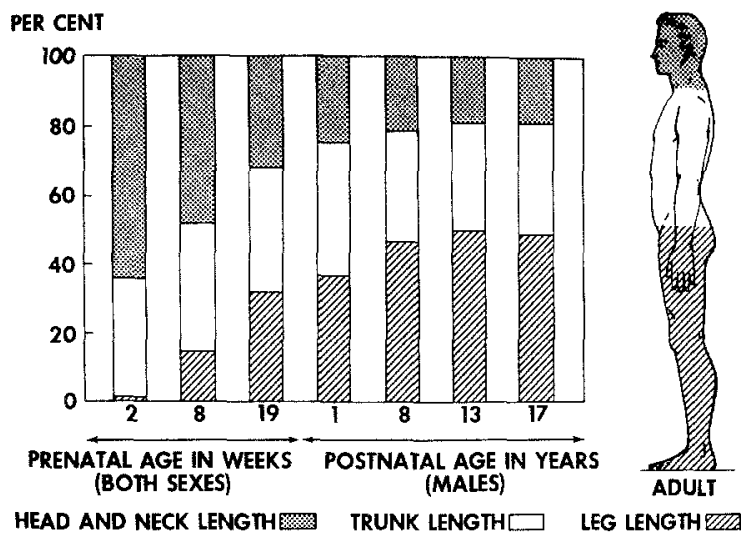

Fig. 1. Percentage distribution of body segments as related to pre- and postnatal development. (Modified from Salzmann, "Principles of Orthodontics.")

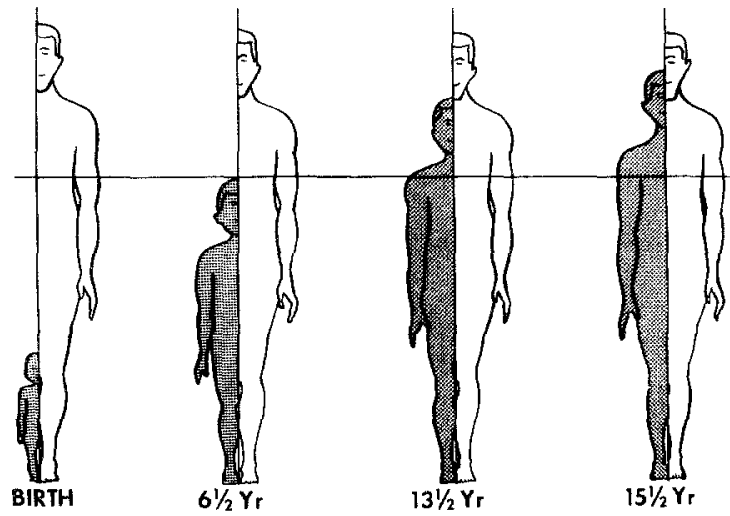

Fig. 2. Increase in total stature at various ages as compared to the adult. (Modified from Chenoweth and Selkirk, "School Health Problems.")
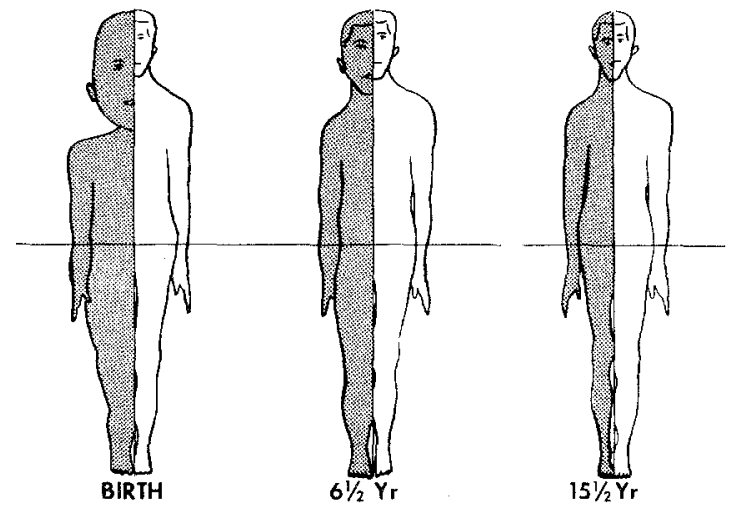

Fig. 3. Developmental change in body proportions as seen in direct comparison between the adult and the newborn, child, and adolescent. (Modified from Chenoweth and Selkirk, "School Health Problems.")
$14 \mathrm{yr}$, total body height increases (in inches) according to the formula: Height = age in $\mathrm{yr} \times 2 \cdot 5+30$ (Weech, 1954).

Age changes in the ratio between sitting (trunk) height and total body height cannot be overlooked when considering the dynamics of changing body proportions (Fig. 4). Sitting height represents about 70 per cent of the total height at birth, but falls rapidly to about 57 per cent at 3 yr. At 13 yr of age in girls and $2 \mathrm{yr}$ later in boys the ratio of sitting height to total body height is about 50 per cent.

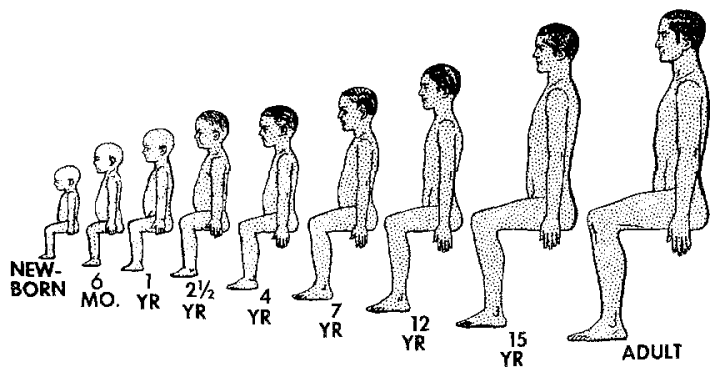

Fig. 4. Changes in sitting height from birth to adulthood.

Longitudinal growth of limb bones occurs as long as the epiphyseal cartilage proliferates; growth ceases when the cartilage ossifies and fuses to the bone segments surrounding it. Since the fusion of epiphyses in the lower extremities occurs earlier in girls than in boys, girls tend to have a lower "sitting heighttotal body height' ratio than boys between 8 and $12 \mathrm{yr}$ and a higher one between 14 and $18 \mathrm{yr}$.

Thus, especially in the early years of life, the infant is markedly elongating in stature. Furthermore, the postural changes of the infant, from a recumbent one to that of a slouched, upright position, is completed within a relatively short period of time. If certain anatomical regions of the child are to be used as 'anchor points' for restraints, then restraints must be adjustable not only for size changes such as in the width of the torso, pelvis, etc., but especially for vertical growth changes so that the anatomical relationships between the restraint and the 
individual are maintained throughout the age range for which the system is intended.

In general, children of either sex are of the same height, weight, and general body proportions up to 10 or $11 \mathrm{yr}$ of age; yet, not infrequently one sees girls slightly taller than their male counterparts even at ages 6-10. Girls tend to have an earlier pubertal growth spurt between 11 and $14 \mathrm{yr}$ and, in general, are taller than boys of this age. In the early to mid-teens, the boys catch up, and then surpass the girls in stature (Watson and Lowrey, 1967). These variations in total height at the 10-14 yr age span reflect the differences in sitting height between boys and girls, and these differences must be considered in any safety design research involving children at these ages.

At birth the head is $\frac{1}{4}$ th the total body length, whereas in the adult it is $\frac{1}{7}$ th (Fig. 5). Also, the trunk is long with the upper limbs being longer than the lower limbs. From the second half

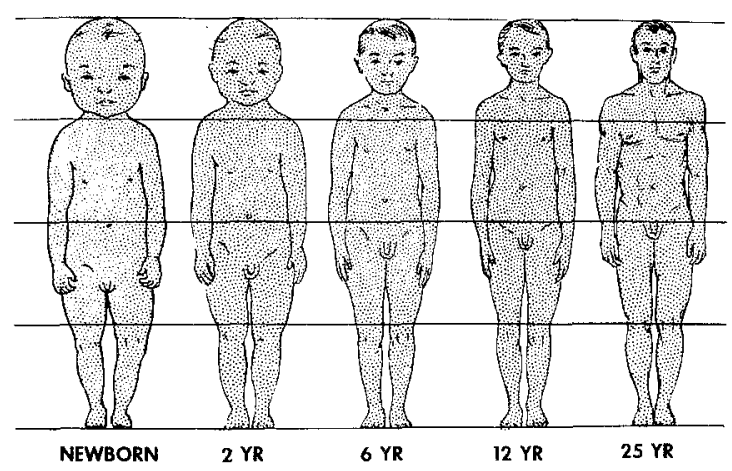

Fig. 5. The proportional changes in body segments with age.

of the first year to puberty the extremities grow more rapidly than the head. At puberty the growth rates of the trunk and limbs are about equal, but the trunk continues to grow in length after limb elongation has declined in the adolescent period. The mid-point of the body is slightly above the umbilicus (navel) in the newborn, and at $2 \mathrm{yr}$ of age the mid-point of the body is slightly below the umbilicus; at $16 \mathrm{yr}$, this mid-point is near the pubic symphysis.

The center of gravity of the child varies according to age, child size, weight, and body form as well as sitting posture. A study by Swearingen and Young (1965), of individuals at ages $5,10,12,15$ and $18 \mathrm{yr}$, indicated that the center of gravity (CG) cannot be located accurately and precisely in groups of seated children. They found that a plot of the $C G$ would fall within an asymmetrically ellipsoidal area. In these children it was found that their $\mathrm{CG}$ was located vertically on the torso well above the lap belt level. This high CG in children must be considered when adult lap belts are used to restrain children, since the greater body mass above the belt may cause the child to whip forward more than in the case of an adult. In a subsequent study of infants aged 8 weeks-3 yr, Young (1968) found that the $\mathrm{CG}$ is located even higher on the body. We would expect also that at the younger ages the variability in CG would also be greater.

\section{THE HEAD AND NECK}

In automotive collisions, the child's head is the body area most frequently and most seriously involved. In a study of children's injury patterns in 14,520 rural automobile accidents involving 31,925 occupants, it was found that children (birth through $11 \mathrm{yr}$ ) had a frequency of 77 per cent head injuries (Moore et al., 1959). This was a much greater frequency than either adolescents (69 per cent) or adults ( 70 per cent) in this study, although it was found that child head injuries were of a more minor variety than either adolescents or adults. In a more recent study of 71,445 occupants of 33,831 cars involved in injury-producing accidents, these earlier findings were confirmed, with children far more likely to incur a head injury than adults (Kihlberg and Gensler, 1967). The vulnerability to injury of an infant's head occurs even prior to birth, as has recently been shown in a study of fetal deaths involving 
restrained and unrestrained pregnant women in auto accidents (Crosby et al., 1968). The reasons for this greater frequency of head injury in children can be demonstrated both anatomically and biomechanically. The child's head is proportionately larger than in the adult (Young, 1966), (Fig. 5). This heavier head mass and resulting higher seated CG in young children, coupled with weaker neck supporting structures, may be, in part, the basis for this higher frequency of head injury.

At birth the facial portion of the head is smaller than the cranium having a face-tocranium ratio of $1: 8$ (cf. adult ratio of $1: 2 \cdot 5$ ). Relative to the facial profile, the newborn forehead is high and quite bulged, due to the massive size of the frontal lobe of the brain (Fig. 6). Thus, in the newborn and infant the face is tucked below the massive brain case (Fig. 7). The large head-small face pattern is noticeable in children even up to ages seven and eight (Fig. 8). Vertical growth of the infant face occurs in spurts as related to both respiratory needs and tooth eruption. These growth spurts occur during the first 6 months after birth, during the 3 rd and 4 th yr, from 7 to $11 \mathrm{yr}$, and again between the 16th and the 19thyr. The first growth spurt is chiefly olfactory as associated with the vertical growth of the upper portion of the nose and nasal cavity. The last spurt is related to adolescent sexual development.

Infant head shape also differs significantly from that of the adult (Fig. 9). In the infant the

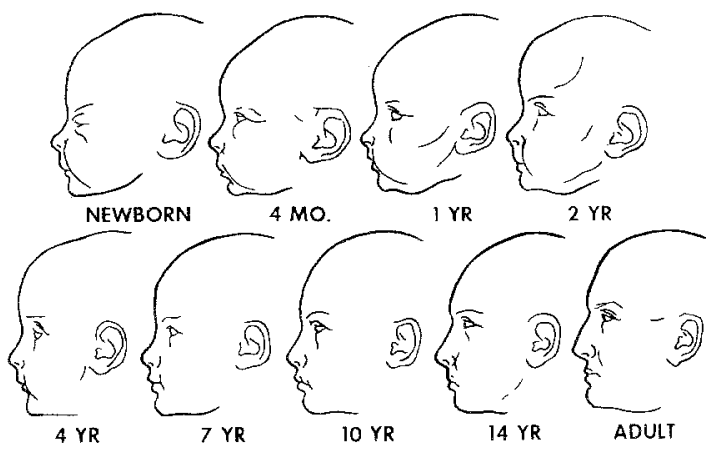

Fig. 6. Soft tissue profile changes of the face and head.

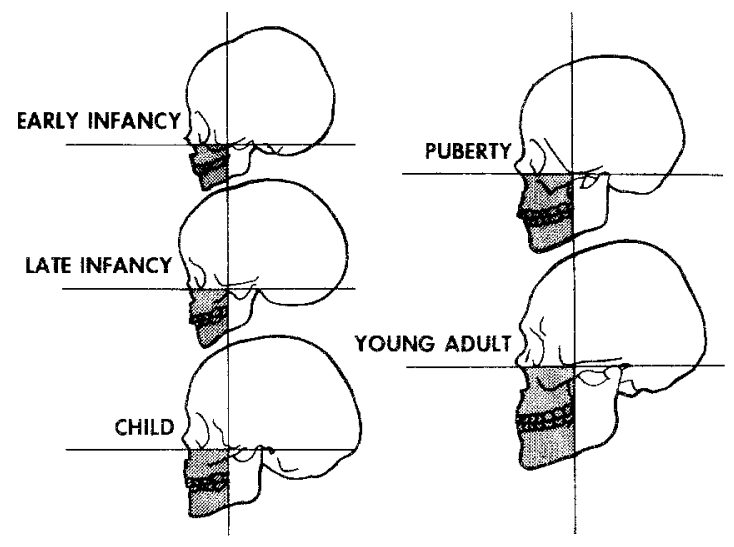

Fig. 7. Sequential changes of various head and face regions.

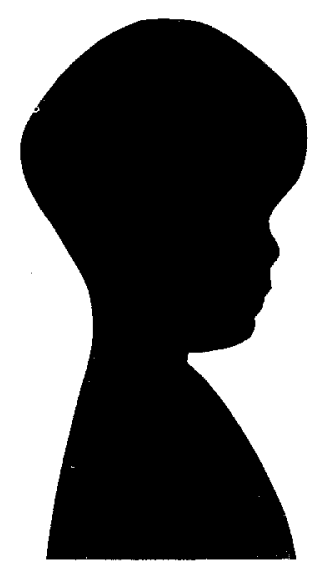

Fig. 8. Silhouette of a normal $5 \mathrm{yr}$ old boy showing the typically large head on the small neck.

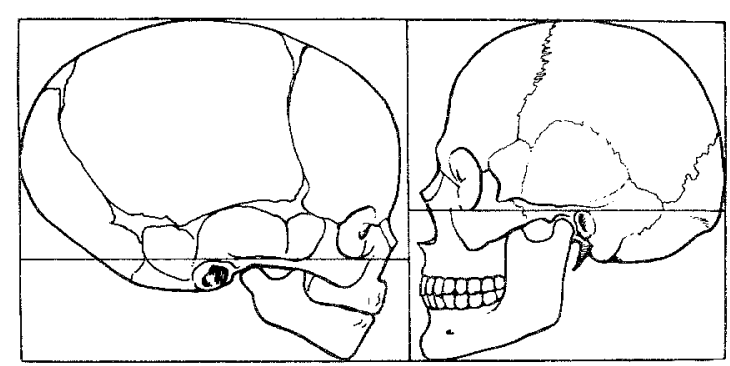

Fig. 9. A comparison of face-braincase proportions in the child and adult. The horizontal line passes through the same anatomical landmarks on both skulls. 
cranium is much more elongate and bulbous, with large frontal and parietal (side) prominences (Fig. 9). At birth the circumference of the head is about 13-14 in. It increases by 17 per cent during the first 3 months of life, and by 25 per cent at 6 months. It increases by about 1 in. during the 2 nd yr, and during the third through 5 th yr head circumference increases by about $\frac{1}{2}$ in. per yr. There is only a 4 in. increase in head circumference from the end of the 1 st yr to the 20th yr (Fig. 10).

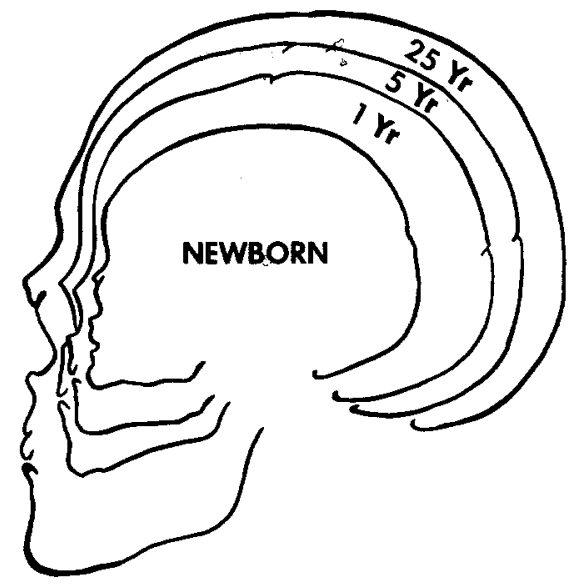

Fig. 10 Skull profiles showing changes in size and shape. (Modified from Morris" "Human Anatomy.")

Head circumference increases markedly during the first postnatal year due to the progressive and rapid growth of the brain as a whole. The important relation of brain size and cranium size can be demonstrated on a percentage basis, which shows that 70 per cent of the adult brain weight is achieved at 18 months, 80 per cent at $3 \mathrm{yr}, 90$ per cent at $5-8 \mathrm{yr}$, and approximately 95 per cent at the 10 th yr. In the adult the average brain weight is $1350 \mathrm{~g}$.

Infant and child skulls are considerably pliable, due to the segmental development and arrangement of the skull bones, plus the flexibility of individual bones which are extremely thin. The skull develops as a loosely joined system of bones formed in the soft tissue matrix surrounding the brain. Junctions between bones are relatively broad and large, leaving areas of brain covered by a thin fibrous sheath and somewhat exposed to the external environment. These 'soft spots' (fontanelles) are several in number and are most obvious in the frontal and posterior skull regions (Fig. 11). The mastoid fontanelle, between the occipital and parietal bones, closes about 6-8 weeks after birth. However, a much larger midline junction between the frontal and parietal bones, i.e. frontal

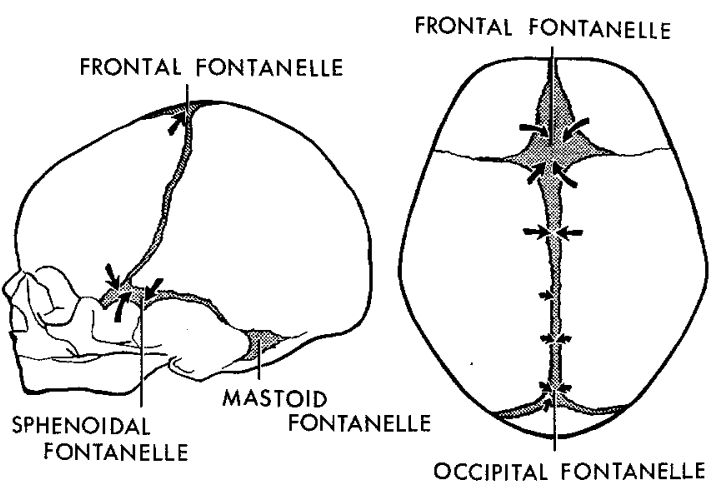

Fig. 11. Size and location of the fontanelles. Arrows indicate direction of fontanelle closure.

fontanelle, is not closed by bone growth until approximately the 17 th month.

At birth all of the potential structures for the development of teeth are present. The early teeth first erupt at about 6 months of age and continue to erupt progressively. The child begins to lose his deciduous teeth about $5-6 \mathrm{yr}$ of age after which they are replaced by the permanent teeth.

Trauma to the jaws of infants or small children, especially in the area where the unerupted teeth are found, can lead to serious problems in tooth eruption, tooth spacing, tooth arrangement and alignment. Traumatic injuries to the child's lower jaw (mandible) may be related to abnormal facial profiles with increasing age. The normal changes in size and position of the lower jaw are dependent upon a growth site in the mandible located near its junction with the skull. If 
this important growth site is significantly traumatized, the normal changes in size and position of the mandible diminish resulting in a smaller mandible and a recessive chin.

Contributing to specific head impact problems are the large head of the child, the relatively soft, pliable, and elastic bones of the cranial vault, and the fontanelles. As compared with the adult, these features make the head of the child less resistant to impact trauma. In a collision, for example, the unrestrained child, because of his large head and high CG, would 'lead with his head.' Crash data covering infants and children up to $4 \mathrm{yr}$ of age indicate that 77 per cent of those who were injured in automobile accidents had head injuries (Kihlberg and Gensler, 1967).

Blunt impact to the head of infants can produce a depression of an entire bone or bones, impinging upon the brain and its nutrient blood vessels, thereby causing considerable neurological problems. Thus, the large head mass relative to total body length, the soft pliable skull structures as well as the clinical problems of oral-facial impacts, involves unique and different approaches to the impact problem of the infant and children.

There are several unique aspects of the anatomy of the child's neck. Neck muscle strength increases with age yet, with the greater head mass perched on a slender neck, the neck muscles generally are not developed sufficiently to dampen violent head movement, especially in children (Fig. 8). The neck vertebrae of children are immature models of the adult. These cervical vertebrae are mainly cartilaginous in the infant, with complete replacement of this cartilage by bone occurring slowly. Articular facets, the contact areas between the vertebrae, are shallow; neck ligaments, as elsewhere in the body, are weaker than in adults. If neck motion exceeds tolerable limits, dislocation of vertebrae and possibly injury to the spinal cord can occur. This combination of anatomical features results in lowered protection of the neck in rapid deceleration, and if the head is rotated or snapped to the side or to the rear, serious damage might occur to the delicate system of critical arteries supplying the head, to nerves, to the vertebrae, or to the spinal cord itself. However, if a child wearing a shoulder restraint was subjected to an abrupt deceleration, his head would whip forward, and it is quite likely that injury to the neck tissues or the spinal cord could occur, particularly if sideward rotation occurs simultaneously because of the greater proportionate head mass, coupled with a weaker neck structure.

By contrast, when an adult is subjected to a similar deceleration the head is bent forward (hyperflexed) with the chin usually striking the chest. Injuries to the adult neck in these circumstances have not yet been documented in either human voluntary experiments or with primates subjected to $175 \mathrm{G}$ impacts (Stapp, 1965).

\section{THE CHEST}

Thoracic injuries in children subjected to impact usually occur to the internal organs due to lack of protection provided by the rib cage. The thoracic walls are thinner and the ribs more elastic in infants and young children than in the adults. Therefore, impact to the thorax of an infant or a small child will produce larger amounts of chest wall deflection onto the vital thoracic organs, e.g. heart, lungs, because of the highly elastic nature of the ribs. As clinicians well know, closed cardiac massage in infants can be performed by using only one or two fingers which well demonstrates the highly elastic nature of the chest wall.

At birth the infant heart lies midway between the top of the head and the buttocks. The long axis of the heart is directed horizontally in the fourth intercostal space with its apex lateral to the midclavicular line. These relationships are maintained until the 4th yr, and later the heart gradually moves downward, due to the elongation of the thorax, 
until it comes to lie at the fifth intercostal space with its apex inside the midclavicular line. Until the 1 st yr, the width (or length) of the heart is no more than 55 per cent of the chest width taken at the xyphoid line. After the 1 st $y r$, heart width is slightly less than 50 per cent of the chest width (Fig. 12).

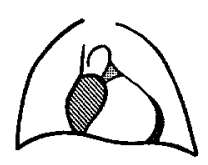

INFANT

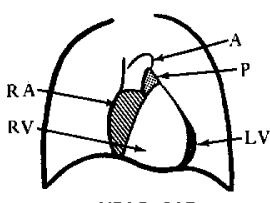

4 YEAR OLD

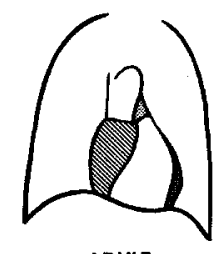

ADULT
Fig. 12. Schematic diagram of the positional changes of the heart within the chest at various ages. (Redrawn from Watson and Lowrey, "Growth and Development of Children.")

At birth the chest is circular, but as the infant grows the transverse diameter becomes larger than the anterior-posterior dimension, giving the chest an elliptical appearance. At birth the chest circumference is about $\frac{1}{2}$ in. smaller than the head. At $1 \mathrm{yr}$ the chest is equal to or exceeds head circumference slightly; after $1 \mathrm{yr}$ the chest becomes progressively larger in diameter than the head. Thus, with the fairly marked change in shape of the infant's chest from that of a circular to an elliptical one, a problem arises in adequate restraint of the upper torso of a child by the use of restraint straps which would not fit tightly to the chest wall. Furthermore, because of the highly elastic nature of the child's chest, a narrow strap placed horizontally around the chest could produce compression injuries of the relatively unprotected thoracic organs.

The highly elastic structure of the thoracic cage is not amenable to direct trauma or loading of narrow restraint straps. The weaknesses of the child are even more pronounced in the infant who must be 'cocooned' for adequate protection, utilizing cradle-board or bassinet devices. In the infant impact tolerances are minimal. When lying down, infants should never be positioned headfacing to the front of the vehicle. The ideal position in a frontal impact of an infant in a cradleboard type of restraint would be facing rearward. The most effective child restraint devices currently available are those which protect the body by distributing the force over a wide area of the head and torso (Heap and Grenier, 1968; and Young and Snyder, 1968), or those which are designed for the rearward-facing child.

Scientists are not entirely in agreement as to the primary biomechanical causation of cardiac trauma during impact in the adult. Researchers such as Stapp (1965) and Taylor (1963) report that pressure is the major factor. However, cardiac rupture has been produced experimentally in animals with the blood volume entirely removed, strongly suggesting that other factors are involved (Roberts et al., 1965). Lasky et al. (1968), studying adult humans involved in steering wheel impacts, believes that aortic laceration occurs at the weakest and narrowest point of the aortic arch, and that this anatomical fact is of biodynamic significance.

Introducing a new consideration, Life and Pince (1968) have demonstrated experimentally in animals that the contractile state of the ventricular myocardium at the instant of impact plays a critical role in whether or not cardiac rupture will occur. Clinical shock with abnormally slow heart and pulse rates (bradycardia) occurs without structural failure in human adult impact tests, and constitutes a primary limitation to the rate of onset (Taylor, 1963).

No thoracic impact data are available for children. Considering the differences between child and adult functional morphology, impact tolerances for the restrained or unrestrained child are probably considerably less than those of the adult.

\section{THE ABDOMEN}

Although statistically meaningful studies on child abdominal injuries have not been 
conducted, the effect of blunt abdominal trauma to children, as compared to adults, has been suggested in the literature. Tank et al. (1968), noted that only cerebral injuries and burns outrank injury to the abdominal organs as a form of serious accidental injury to children. In adults, blunt injury to the abdominal viscera presents the most difficult diagnosis and treatment, and results in the highest mortality rate (Fonkalsrud, 1966; Orloff, 1966). Thus, any blunt abdominal injury can be potentially serious, but such injuries to the infant and child are much more critical due to their developing and immature structure, large organ relationships, and almost complete lack of overlying muscle or skeletal protection.

The bulge of the newborn abdomen is accentuated by the abdominal viscera pushing forward during respiration against the weak and atonic muscle wall of the abdomen. The right side of the infant and newborn abdomen is especially enlarged due to the low position of the liver which occupies $\frac{2}{5}$ ths of the abdominal cavity. Along the midclavicular line the liver is approximately $2 \mathrm{~cm}$ below the costal margins in the newborn; $1 \frac{1}{2} \mathrm{~cm}$ below the margin for the remainder of the $1 \mathrm{st}$ $\mathrm{yr}$; and $1 \mathrm{~cm}$ below from 18 months to 6 yr. After about the 6th-7th yr, the liver is seldom palpable except in abnormal cases. On a weight basis, the liver of the newborn comprises 4 per cent of the total body weight, and by puberty weighs ten times as much (Watson and Lowrey, 1967). The liver, although considered as an abdominal organ, lies almost entirely deep to the right lower ribs. The highly elastic ribs of the child offer minimal protection for this organ from impact.

Posteriorly, a similar relative migration of the bony thorax downward occurs to provide some protection for the spleen, kidneys, and suprarenal glands as the infant ages. At birth, for example, the kidneys occupy a large portion of the posterior abdominal cavity owing to the relatively large size.

In the newborn, the urinary bladder lies close to the lower abdominal wall with only its lower portion located behind the pubic bones. During childhood, much of the bladder decends into the pelvic area where it is more protected by the bony pelvis.

Again, many of the child abdominal viscera are relatively unprotected by bone as compared to the adult. The bladder is located higher, outside of the pelvic area, the liver and kidneys are relatively exposed, all being more available to traumatic insult. With the highly elastic ribs minimally protecting the liver, impacts to the right side of the lower chest or upper abdomen can and do produce serious traumatic liver injuries. The liver is an organ which is not well designed for withstanding traumatic insults even in the adult. Traumatic liver injuries produce the highest mortality rate of any abdominal organ (Di Vincenti et al., 1968). With the smaller chest and pelvis of the child, less of the abdominal contents are protected by the rib cage and bony pelvis, and can be more easily injured.

Dimensions of the abdominal area also differ from that of the adult, both proportionately and in relation to position of body organs. Abdominal girth, in general, is about the same as that of the chest during the first 2 yr of life. After $2 \mathrm{yr}$, increases in abdominal circumference at the umbilical level do not keep pace with the increases in thoracic girth. Pelvic breadth is another dimension which is less subject to variations in body posture and tonic activity of the muscular abdominal wall. The maximum distance between the external margins of the iliac crests is approximately $3 \mathrm{in}$. at birth, $5 \mathrm{in}$. at $1 \mathrm{yr}, 7 \mathrm{in}$. at $5 \mathrm{yr}$, and $9 \mathrm{in}$. at $10 \mathrm{yr}$. Generally, in the early part of infancy there is little change in trunk form, but after the assumption of erect posture there is a relative reduction in the anterior-posterior diameter of both of the thoracic and abdominal regions, accompanied by a decrease in the relative size of the umbilical region and a relative increase in the lumbar region. These changes continue throughout childhood and early adolescence. 


\section{THE VERTEBRAL COLUMN}

Normal development of erect posture involves a gradual transition from the early crawling stages involving interrelationships of the extremities, spine, and pelvis, to the well-balanced weight-bearing relationships typical of the adult. When the infant first stands, the pelvis is tilted far forward on the thighs and an erect posture is first attained in infancy concurrent with the development of the lumbar (low back) curve. As the result of this lumbar curve, combined with increased tonic activity of abdominal wall muscles the infant develops his characteristic swayback and abdominal prominence which is maintained throughout pre-school years. The infant pelvis gradually rotates upward and forward beginning to establish an adultlike posture. The curvature of the sacrum as seen in the adult is already present at birth; however, in infants the vertebral column above the sacrum is usually straight (Fig. 13). Early in infancy the baby can raise his head while lying prone, and the cervical (neck) curve first becomes well established as the head is held erect and cervical muscles become developed and increase their tonic activity. By the 3rd or 4th month the infant can sit with support and by the 7 th month can be expected to sit alone. At 8 or 9 months, the infant usually can stand with support and then can stand without assistance by 10-14 months.

Typically, for the adults lap belts have been designed for use in the upright seated position and to fit between the upper thigh and front of the pelvis. If adults are slouched, they cannot properly wear the lap belt to fit in this thigh-pelvic area. Yet, very few children sit 'straight.' The curvature of the vertebral column and the tilt of the pelvis are not conducive for bolt upright posture in children. In addition, when a child is seated the distance between the front ends of the iliac crests (the anterior superior iliac spines) and the fleshy front of the thighs is minimal and often there is not adequate space for the lap belt. Thus, the belt 'rides up' onto the lower abdominal wall.

Perhaps the best example of structural differences of children which require unique restraint solutions is typified by the pelvis.
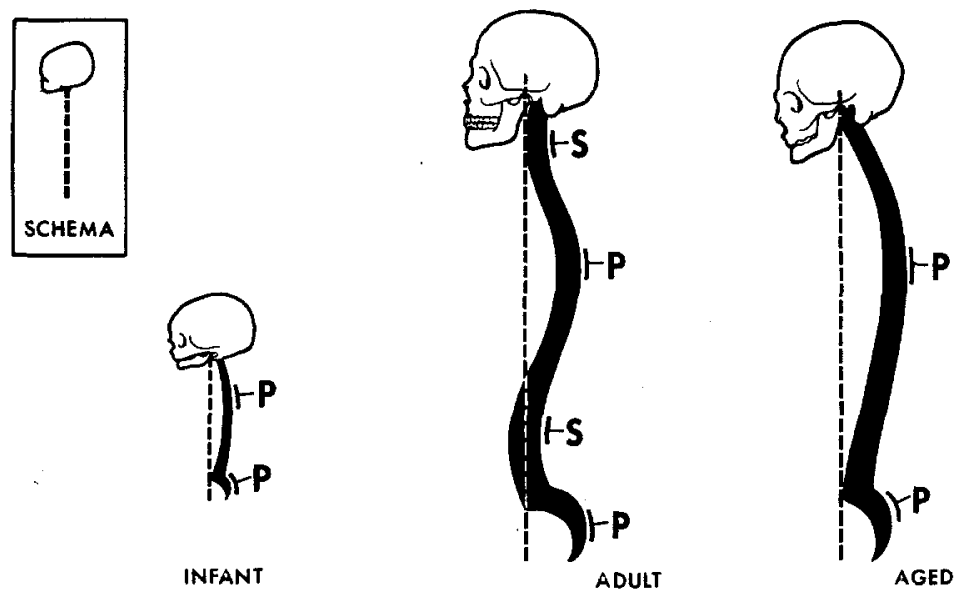

Fig. 13. Curvature of vertebral column emphasizing the development of primary curvatures (P) and secondary curvatures $(S)$. Note: in the infant there are only two primary curves, i.e. thoracic and sacral. In the adult there are secondary curves in the cervical and lumbar regions. In the aged only the primary curves persist. (Modified from Johnson and Kennedy, "Radiographic Anatomy of the Human Skeleton.") 
In the adult, the prominent anterior superior iliac spines are used as anatomical anchor points. But in children these spines are not well developed until about $10 \mathrm{yr}$, and basically do not yet exist. Rather this anterior pelvic area is a broad gentle curve without a prominent spine as in the adult. Thus, the lap belt does not have a good anatomical anchor point and with the small pelvic contact area, especially when the child is seated, the lap belt contacts a significantly large portion of the soft abdominal wall. At impact, as the torso is flexing over the belt, the pelvic area will submarine under the belt because of the lack of well developed iliac spines. Thus, in an impact situation a lap belt on a child could actually produce serious internal abdominal injury, for the belt could slip up onto the soft vulnerable abdominal area. This lack of firm structural anatomical anchor points in children is a significant problem. To effectively protect the child (rather than actually contribute to his injuries), other ways to distribute the force over the body must be considered.

\section{THE LIMBS}

In considering the growth of the extremities it is necessary to examine factors of skeletal embryology and subsequent dimensional changes (Scammom and Calkins, 1929). Considering first the trends in dimensional growth of the limbs, it is generally noted that the lower limbs increase in length more rapidly than do the upper limbs. At about $2 \mathrm{yr}$ of age, for example, their lengths are equal but in the adult the lower limb is about $\frac{1}{6}$ th longer than the upper limb. The adult relations of the different limb segments are well established prenatally; however, there is some reduction in the relative length of the hand and of the foot after birth. At birth the lower limb forms about 15 per cent of the body volume and in the adult reaches about 30 per cent. In contrast, the upper limb constitutes about 8 per cent of the body weight at birth and maintains this same proportionality thereafter.

As in the skull, the long bones of the extremities pass through successive developmental stages which, when compared to adult morphology, make the limb bones less tolerable to trauma. In early development before birth, long bones are typically represented by a shaft of bone which grows in diameter by addition of new bone on its surface with concomitant erosion within the shaft. This development of the shaft can best be described as a tube that progressively increases in diameter. Impact tolerances of children's bones are dependent upon the changing girth of the bone and relative proportions of the marrow cavity and bony walls, as well as the proportions of inorganic and organic materials that form bone tissue. In the early development of bone tissue, organic materials outweigh inorganic components. The degree of flexibility or torsional strength of the bone itself is directly related to the organic component of the bone structure. The preponderance of organic material continues through adolescence after which there is a gradual buildup of inorganic bone substance.

Change in length of long bones is a function of the continued growth of epiphyseal cartilage. In the early development of a long bone the shaft is capped on both ends by cartilage. From late fetal life through puberty bone tissue appears in the cartilage at either end of the shaft but does not attach to the shaft. There is a remaining cartilaginous epiphyseal plate between the bony shaft and the bony epiphyseal ossification center at each end. The surface of the epiphyseal cartilage in contact with the long bone shaft continues to grow which effectively moves or pushes the epiphyseal bone cap away from the shaft. This activity of the epiphyseal cartilage accounts for increases in length of the long bone. Finally, when the adult length is attained for a specific bone as influenced by sex, race, nutrition, and endocrine balance, the cartilage 
of the epiphyseal plate stops proliferation and begins to ossify. Thus, the bony epiphyseal cap is united to the shaft. In females the epiphyses unite sooner so that growth in length ceases earlier by about 2-3 yr when compared to males of similar ages. But even in the male most of the fusions of long bone epiphyseal cartilages are completed at about the 20th yr. Obviously since bone length is a factor of epiphyseal cartilage growth, traumatic displacement of the cartilage out of line with the normal long axis of the bone can lead to gross limb distortion and malformations.

\section{BIOMECHANICAL PROPERTIES OF TISSUES}

Various workers have indicated that the tensile strength of tissues is less in children than in adults. Tissue strengths have been found to be the strongest at about $20 \mathrm{yr}$ of age. Biomechanical testing has been conducted on such tissues and organs as muscle (Katake, 1961), peripheral nerve (Okamoto, 1955) urinary bladder (Asmai, 1961) gut wall including stomach, esophagus, and intestine (Fukuyama, 1961; Nonogaki, 1960; Wasaki, 1953), costal cartilages (Ko, 1953), skin (Ridge and Wright, 1966), blood vessels (Frasher, 1966; Mochizuki, 1952), tendons (Van Brocklin and Ellis, 1965; Blanton, 1964; Takigowa, 1953) and bone (Evans, 1957; Hirsch and Evans, 1965; Herrmann and Liebowitz, 1969; Kraus, 1968). Studies involving the mechanical properties of tissues have recently been reviewed by Fung (1968). Although adult cadaver impact tests have been conducted, no experimental impacts using young cadavers to determine human tolerances have been carried out.

\section{CONCLUSIONS}

Infants and children are not miniature adults. Their anatomy differs from the adult in a number of ways which cannot be overlooked in the proper design of occupant restraint systems specific to their age. Safe vehicular packaging for the infant and child requires protective devices based on child anatomy rather than on the anatomy of the adult. Within the framework of automobile safety design we have emphasized that:

(1) The frequency of head injuries in children involved in automobile accidents may be due to the child's proportionately large head and higher center of gravity. As a consequence, infants and children restrained by a lap belt have a greater chance of being projected over the restraining belt because the $C G$ and body fulcrum is located above the belt location.

(2) Observations that the child's head is relatively massive and supported poorly from below have been implicated in head snapping with rapid body deceleration. Such sudden snapping or rotation of the relatively unrestrained child's head can traumatize related nerves, blood vessels, and spinal cord segments.

(3) Contributing to brain injuries of the young child is the relative lack of skull protection since, early in life, the skull is not an intact bony case for the brain but is a series of broadly spaced elastic bones.

(4) Growth rates of different parts of the body vary with age. For example, the midpoint of the body is above the navel at birth, slightly below it at $2 \mathrm{yr}$, and nearer the pubic bones at $16 \mathrm{yr}$.

(5) Since growth of the child is dependent upon the normal activity of growth centers, protection of these centers is vital. $\mathrm{Ab}$ normalities of body stature and limb mobility might result from injury to growth centers of the extremities. Similarly, in the head, the arrangement of teeth as well as the facial profile can be affected by traumatic injuries to the facial growth centers.

(6) Differences in size, structure, shape, and biomechanical properties of the infant, child, and adult pelvic skeleton are clearcut and must be considered in terms of proper lap belt design, position, and vehicle anchorage. Key differences include the absence of the anterior superior iliac spines and sufficient 
space in the pelvic-thigh angle for adequate positioning of the adult lap belt on the child.

(7) Unlike the adult, the organs of the chest are housed in an elastic and highly compressible thoracic cage. Organs as the lungs and heart are extremely vulnerable to nonpenetrating impacts to the chest. The smaller rib cage also means less protection is offered to larger abdominal organs which would normally receive some protection from the larger stronger rib cage of the adult. The highly elastic structure of the thoracic cage is not amenable to direct trauma or loading of webbed restraints in children.

(8) The most effective restraint systems for children are those which distribute impact forces over a large portion of the body.

The general principles for child and infant vehicular restraint systems have been presented in this paper to emphasize the basic anatomical differences between the adult and child that must be considered in providing effective and flexible child vehicular restraints.

Acknowledgements-This research was supported, in part, by funds from the Automobile Manufacturers Association through the Highway Safety Research Institute of The University of Michigan, and by USPHS Grant Number HD 00178 from the National Institute of Child Health and Human Development.

\section{REFERENCES}

Asami, I. (1961) Study on the strength of human urinary organs. J. Kyoto Pref. Univ. Med. 70, 2.

Blanton, P. (1964) Tensile strength of fetal and adult human tendons. M. S. Thesis. Dept. of Anatomy. Baylor Univ., Dallas.

Chenoweth, L. B. and Selkirk, T. K. (1937) School Health Problems. Crofth, New York.

Crosby, W. M., Snyder, R. G., Snow, C. C. and Hanson, P. G. (1968) Impact injuries in pregnancy - I. Experimental studies. Am. J. Obstet. Gynec. 101, 100-110.

DiVincenti, F. C., Rives, J. D., Laborde, E. J., Fleming, I. D. and Cohen, I. (1968) Blunt abdominal trauma. J. Trauma 8, 1004-1013.

Evans, F. G. (1957) Stress and Strain in Bones. Thomas, Springfield, Ill., $245 \mathrm{pp}$.

Fonkalsrud, E. W. (1966) Acute trauma in infants and children. In Early Management of Acute Trauma. (Edited by A. Nahum), pp. 180-192. Mosby, St. Louis.

Frasher, W. G. (1966) What is known about the physiology of large blood vessels. Biomechanics, ASME Symp., New York.
Fukuyama, Y. (1961a) Age changes of the strength for tension of human gastric walls. $J$. Kyoto Pref. Univ. Med.69, 1.

Fukuyama, T. (1961b) Studies on the strength for bursting the walls of human and animal oesophages. $J$. Kyoto Pref. Univ. Med. 69, 1.

Fung, Y. C. (1968) Biomechanics. Appl. Mech. Rev. 21, 1-20.

Herrmann, G. and Liebowitz, H. (1969) Mechanics of bone fracture, In Treatise on Fractures. (Edited by H. Liebowitz), Vol. 7. Academic Press, New York (In press).

Hirsch, C. and Evans, F. G. (1965) Studies on some physical properties of infant compact bone. Acta orthop. scand. 35, 300-313.

Johnson, W. H. and Kennedy, J. A. (1961) Radiographic Anatomy of The Human Skeleton. Williams and Wilkins, Baltimore.

Katake, K. (1961) Studies on the strength of human skeletal muscles. J. Kyoto Pref. Univ. Med. 69, 463.

Kihlberg, J. K. and Gensler, H. R. (1967) Head Injuries in Automobile Accidents Related to Seat, Position, and Age. Cornell Aeronautical Laboratory, Inc.

Ko, R. and Takigawa, M. (1953) The tension test upon the costal cartilage of a human body. J. Kyoto Pref. Univ. Med. $\mathbf{5 3}, 1$.

Kraus, H. (1968) On the mechanical properties and behavior of human compact bone. In Advances in Biomedical and Medical Physics. (Edited by S. N. Levine), Vol. 2. Wiley-Interscience, New York.

Krogman, W. M. (1960) Height, weight and body growth of American white and American negro boys at Philadelphia, aged 6-14 yr. Philadelphia Center for $R e-$ search in Child Growth, Philadelphia, $P a$.

Krogman, W. M. (1941) Growth of man. In Tabulate Biologicae. Vol. 20. Vitgeverij Dr. W. Junk, Den Haag.

Krogman, W. M. and Johnston, F. E. (1965) The physical growth of Philadelphia white children, age 7-17 yr. Philadelphia Center for Research in Child Growth, Philadelphia, Pa.

Heap, S. A. and Grenier, E. P. (1968) The design and development of a more effective child restraint concept. Soc. Automotive Engrs, New York. Automotive Engineers Congress, Detroit, January 8-12. SAE preprint No. 680002.

Lasky, I., Siegel, A. W. and Nahum, A. M. (1968) Automotive cardio-thoracic injuries: a medicoengineering analysis. Soc. Automotive Engrs. New York. SAE preprint No. 680052.

Life, J. S. and Pince, B. W. (1968) Response of the canine heart to thoracic impact during ventricular diastole and systole. J. Biomechanics 1, 169-173.

Martin, W. E. and Thieme, F. P. (1954) The functional body measurements of school age children. A Joint Project of the U.S. Office of Education, The University of Michigan and the National School Service Institute. Chicago, Ill.

Meredith, H. W. (1963) Change in the stature and body weight of north American boys during the last $80 \mathrm{yr}$. Advances in Child Development and Behavior. Vol. 1. Academic Press, New York.

Mochizuki, T. (1952) On the mechanical strength of the human blood vessels. J. Kyoto Pref. Univ. Med. 52, 1 . 
Moore, J. O., Tourin, B., Garrett, J. W. and Lilienfeld, R. (1959) Child injuries in automobile accidents. Paper presented at 14 th Int. Conf. Pediatrics, Montreal, Canada. Also in Traffic Safety Res. Rev. 4, 16-21.

Morris, H. (1966) Morris' Human Anatomy. (Edited by B. J. Anson), 12th Edn. Blakiston, New York.

National Safety Council (1968) Accident Facts. Chicago, Ill.

Nonogaki, F. (1960) Study on the strength of the human esophageal wall. J. Kyoto Pref. Univ. Med. 67, 5.

Okamoto, T. (1955) Study on strength of peripheral nerve tissue of human beings and various animals. J. Kyoto Pref. Univ. Med. 58, 6.

Orloff, M. J. (1966) Abdominal Injuries, Early Management of Acute Trauma. (Edited by A. Nahum), pp. 148-161. Mosby, St. Louis.

Ridge, M. D. and Wright, V. (1966) Mechanical properties of skin. A bioengineering study of skin structure. J. appl. Physiol. 21, 1602-1606.

Roberts, V. L., Moffat, R. C. and Berkas, E. M. (1965) Blunt trauma to the thorax-mechanism of vascular injuries. Proc. 9th Stapp Car Crash Conf. pp. 3-12. University of Minnesota Press.

Salzmann, J. (1943) Principles of Orthodontics, Lippincott, Philadelphia, Pa.

Scammon, R. E. and Calkins, L. A. (1929) The Development and Growth of the External Dimensions of the Human Body in the Fetal Period. University of Minnesota Press.

Stapp, J. P. (1965) Trauma caused by impact and blast. Clin. Neurosurg. 12, 324-343.

Stuart, H. C. and Stevenson, S. S. (1950) Physical Growth and Development. Quoted in Nelson, MitchellNelson Textbook of Pediatrics, Philadelphia, 1950. Reprinted in Documents-Geigy, Scientific Tables, 5th Edn, 1959.

Swearingen, J. J. and Young, J. W. (1965) Determination of Centers of Gravity of Children, Sitting and Standing. Rep. No. AM 65-23 August, 1965, Civil Aeromed.
Res. Inst., Federal Aviation Agency, Oklahoma City, Okla.

Takigawa, M. (1953) Study upon strength of human and animal tendons. J. Kyoto Pref. Univ. Med. 53, 6.

Tank, E. S., Eraklis, A. J. and Gross, R. E. (1968) Blunt abdominal trauma in infancy and childhood. J. Trauma. 8, 439-448.

Taylor, E. R. (1963) Biodynamics: Past, Present and Future. 6571 st Aero-medical Res. Lab., Holloman AFB, New Mexico. Rep. No. ARL-TDR-63-10.

Van Brocklin, J. D. and Ellis, D. G. (1965) A study of the mechanical behavior of toe extensor tendons under applied stress. Archs phys. Med. Rehabil. 369-373.

Wasaki, T. (1953) Study on the strength of the human intestinal walls. J. Kyoto Pref. Univ. Med. 52, 5.

Watson, E. H. and Lowrey, G. H. (1967) Growth and Development of Children. 5th Edn Year Book Publishers, Chicago.

Weech, A. A. (1954) Signposts on the highway of growth. A.M.A. Am. J. Dis. Child. 88, 452.

Young, J. W. (1968) Personal communication. Unpublished Infant C. G. data.

Young, J. W. (1966) Selected Facial Measurements of Children for Oxygen Mask Design. Office of A. Med. Federal Aviation Agency, Oklahoma City, Rep. No. AM66-9.

Young, J. W. and Snyder, R. G. (1968) Unpublished test data. Ford Motor Co., Dearborn.

\section{Note added in proof}

Since the writing of this report, another contribution on the chronology of human anthropometric change has come to the authors' attention who consider it to be a source of valuable background data relevant to most sections of their paper:

McConville, J. T., Source data for the design of simulated human body forms. Anthropology Project PH62-329, Antioch College, Yellow Springs, Ohio, $55 \mathrm{pp}$. 